\title{
UTILIZATION OF FINE RESOLUTION SATELLITE DATA FOR LANDSLIDE SUSCEPTIBILITY MODELLING: A CASE STUDY OF KASHMIR EARTHQUAKE INDUCED LANDSLIDES.
}

\author{
Muhammad Zeeshan Ali ${ }^{1 *}$, Hone-Jay Chu ${ }^{1}$, Saleem Ullah², Muhammad Shafique ${ }^{3}$ and Asad Ali ${ }^{2}$ \\ 1. National Cheng Kung University, Tainan, Taiwan. (zeeshanktk1992@yahoo.com*, honejaychu@geomatics.ncku.edu.tw ) \\ 2. Institute of Space Technology, Islamabad, Pakistan. (saleem.ullah@grel.ist.edu.pk, asad06@ gmail.com ) \\ 3. National Centre of Excellence in Geology, University of Peshawar, Peshawar, Pakistan. (shafique@uop.edu.pk )
}

Commission VI, WG VI/4

KEY WORDS: Landslide Inventory, Support Vector Machine, Influential Factors, Logistic regression, Landslide Susceptibility map

\begin{abstract}
:
The 2005 Kashmir earthquake has triggered thousands of landslides which devastated most of the livelihood and other infrastructure in the area. Landslide inventory and subsequently landslide susceptibility mapping is one of the main prerequisite for taking mitigation measure against landslide effects. This study has focused on developing most updated and realistic landslide inventory and Susceptibility mapping. The high resolution data of Worldveiw-2 having spatial resolution of $0.4 \mathrm{~m}$ is used for landslide inventory. Support Vector Machine (SVM) classifier was used for landslide inventory developing. Total 51460 number of landslides were classified using semi-automatic technique with covering area of $265 \mathrm{Km}^{2}$, smallest landslide mapped is covering area of $2.01 \mathrm{~m}^{2}$ and the maximum covered area of single landslide is $3.01 \mathrm{Km}^{2}$. Nine influential causative factors are used for landslide susceptibility mapping. Those causative factors include slope, aspect, profile curvature, elevation, distance from fault lines, distance from streams and geology. Logistic regression model was used for the Landslides susceptibility modelling. From model the highest coefficient was assigned to geology which shows that the geology has higher influence in the area. For landslide susceptibility mapping the $70 \%$ of the data was used and 30\% is used for the validation of the model. The prediction accuracy of the model in this study is $92 \%$ using validation data. This landslide susceptibility map can be used for land use planning and also for the mitigation measure during any disaster.
\end{abstract}

\section{INTRODUCTION}

Landsliding is one of the most frequent and destructive natural hazards in the mountainous regions. In many countries, causalities from landslides are greater in numbers than from other natural disasters like floods, earthquakes, hurricanes and tsunami (Yilmaz 2009). Many studies have compared the characteristics of earthquake and rainfall-triggered landslide inventories and focus on mapping landslides triggered by rainfall after major earthquakes (Wei et al. 2018). World widely the earthquake has widespread thousands of large landslides such as Chi Chi earthquake (Weissel and Stark 2001), the 2005 Kashmir earthquake (Kamp et al. 2008; Lodhi 2011; Shafique et al. 2016), Wenchuan earthquake of 2008 (Chigira et al. 2010; Gorum et al. 2011) and Kumamoto earthquake of 2016 (Xu et al. 2018). Due to the shaking of earth during Earthquake the mountainous surface lose their shear strength which occur the large landslides in the earthquake effected area.

Landslide inventory developing and susceptibility mapping is very important to separate the area of susceptible and stable area to mitigate the property and infrastructure in the area. For developing landslide inventory different techniques are applied by different researchers like manual digitization, Pixel based classification of landslides and also the Object based image classification techniques (Martha et al. 2010; Lodhi 2011; Basharat et al. 2016). Spatial resolution of satellite imagery is important to define the magnitude and extent of landslide area, the fine resolution data can detect small landslides but can only work on small area due to high prices of imagery (Ali et al. 2017). Different spatial resolution data has been used for this study area for developing landside susceptibility map like ASTER has been used by (Kamp et al 2010) Landsat is used by (Lodhi 2011).

Landslide susceptibility mapping is the distribution of the area into different zones on the basis of the probability of the occurrence of the landslide according to the factors which are taken during the modelling. To develop landslide susceptibility map different influential factors are used by different researchers with landslide inventory and those factors also varying on geographical region. Worldwide different causative factors are used like Elevation, Geological formations, Lithology's, Fault lines, Slope Angle, Aspect, Profile Curvature, Plan Curvature, Topographic Wetness Index, Soil Wetness Index, Normalized difference vegetation index (NDVI), Distance to the streams. Globally different models are used for landside susceptibility modelling like statistical index (Kavzoglu et al. 2015), analytical hierarchy process (AHP) model (Yalcin et al. 2011; Pourghasemi et al. 2012), frequency ratio (Yalcin et al. 2011), logistic regression (Devkota et al. 2013; Pourghasemi et al. 2013; Raja et al. 2017), support vector machine (SVM) (Kavzoglu et al. 2014; Bui et al. 2015), certainty factor (Devkota et al. 2013), weights of evidence (Mohammady et al. 2012; Soofastaei et al. 2016) random forests (RF) (Stumpf and Kerle 2011), fuzzy set (logic) (Dragićević et al. 2015) and artificial neural network (ANN) (Yilmaz 2010; Bui et al. 2015). The logistic regression model is multivariate model which give us coefficient which shows the impact of individual factor on the landslide in the area (Chauhan et al. 2010).

The Kashmir earthquake of 2005 has induced hundreds of large and thousands of small landslides in the area. Due to the rough 
terrain the area is most prone to landslides. Many studies have been done using moderate resolution data like Landsat and ASTER for landslide inventory developing and also for topographic attributes $30 \mathrm{~m}$ DEM has been used (Kamp et al. 2008; Owen et al. 2008), . The aim of this study is to develop landslide inventory using fine resolution. Furthermore, the landslide inventory will be used to develop more accurate and realistic landside susceptibility map for the area.

\section{Study Area}

The study is conducted in the main effected area of Kashmir earthquake 2005, where thousands of peoples were killed and many people have lost their houses during this high magnitude earthquake. The Neelam rivers is flowing within the capital of Azad Kashmir which is named the city of Muzaffarabad.

Geologically the area is very rich due to different geological formation but most of the area is covered by the Murree and
Muzaffarabad formation. In the area geological formations are playing important role in the occurrence of landslides. The study area is covered with the high mountainous peaks, the elevation range is 608 to $2559 \mathrm{~m}$ (above sea level). The area is composed of three fault line Murree fault, Panjal fault and Muzaffarabad fault line. Due to the mountainous region the area is usually hit by heavy monsoon rains. The annual rate of precipitation is 1500 $\mathrm{mm}$. The study area has less steep slopes, the area is mostly at the slope angle of $\left(10^{\circ}\right.$ to $\left.25^{\circ}\right)$ and very less area has high steep slope like $\left(>50^{\circ}\right)$. Due to the mountainous terrain the area has diverse weather pattern. The minimum and maximum temperature during summer is $22.1^{\circ}$ and $37.6^{\circ}$ and during winter the temperature is $3.2^{\circ}$ and $15.9^{\circ} \mathrm{C}$.

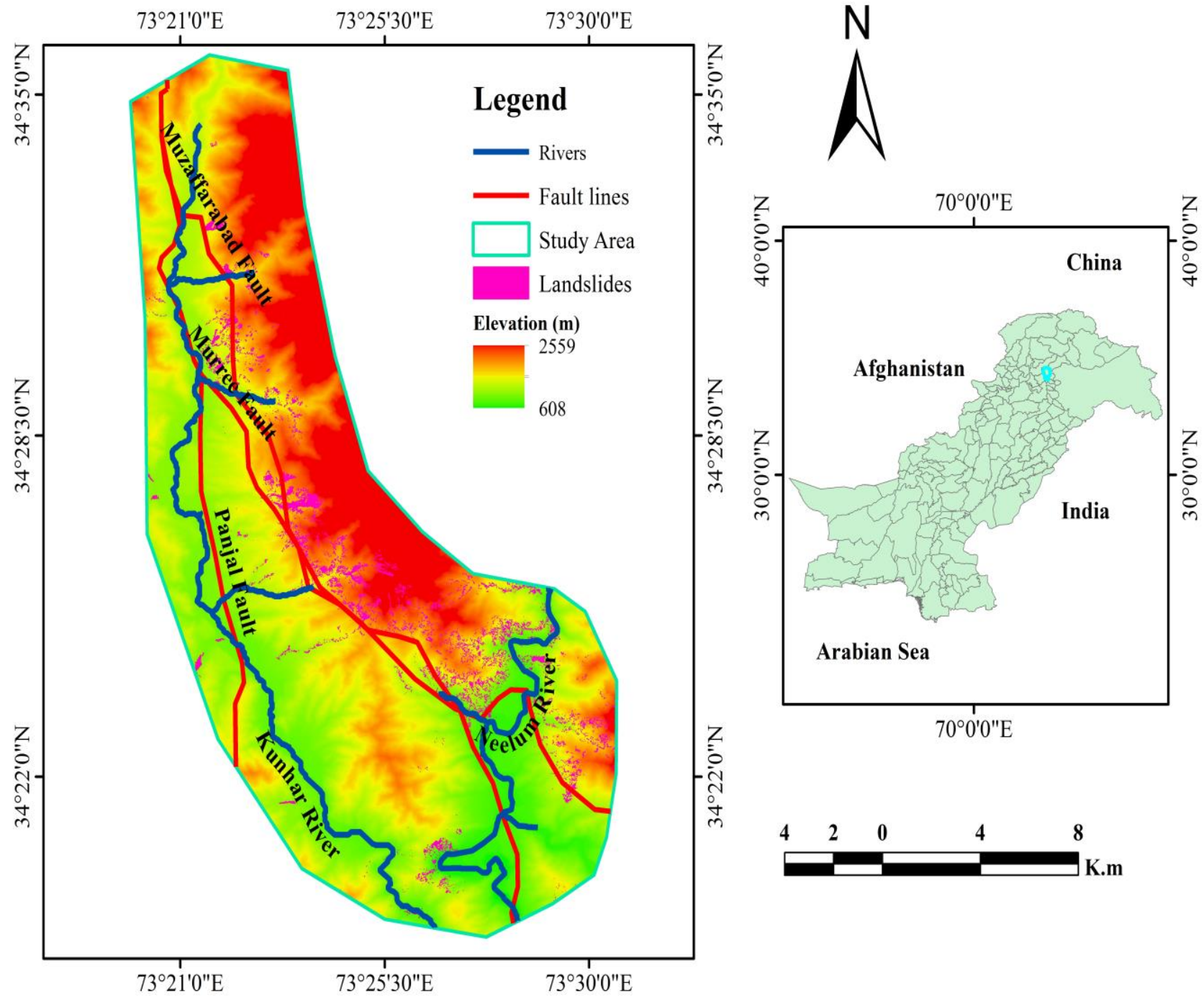

Figure 1: Location map of Study area

\section{Material and Methods}

For this study, we have used high resolution imagery having spatial resolution of $0.4 \mathrm{~m}$ and spectral resolution of 4 bands which was used to develop more updated and more realistic landslide inventory. High resolution Digital Elevation Model (DEM) is used to develop topographic attributes like (Slope,
Aspect, Curvature, extraction of streams using flow accumulation). Other data was collected from the relevant departments like geology and fault line dataset.

Landslide inventory was develop using pixel based image classification technique which is also called is semi-automatic technique for developing landslide inventory. 
Influential factors are one of the important input factors for landslide susceptibility modelling. For this study we have used logistic regression model which is the mathematical model and shows the probability of the occurrence of landslide in the area on the basis of the input independent predictors (Raja et al. 2017, Wu et al. 2017).

$\operatorname{logit}(Y)=\ln \left[\frac{Y}{1-Y}\right]=\beta_{0}+\beta_{1} X_{1}+\beta_{2} X_{2}+\cdots+\beta_{n} X_{n}$
Where $\beta_{0}$ is constant of equation, and $\beta_{1,} \beta_{2}, \beta_{3} \ldots \ldots \beta_{n}$ are the independent variables coefficients, $X_{1}, X_{2}, X_{3} \ldots . . . X_{n}$ are the independent variables which are actually causative factors in case of landslide susceptibility mapping. The dependent variable $(Y)$ for our analysis is the presence or absence of a landslide, which is acquired from landslide inventory. Figure 2 shows the methodlogy of the study.

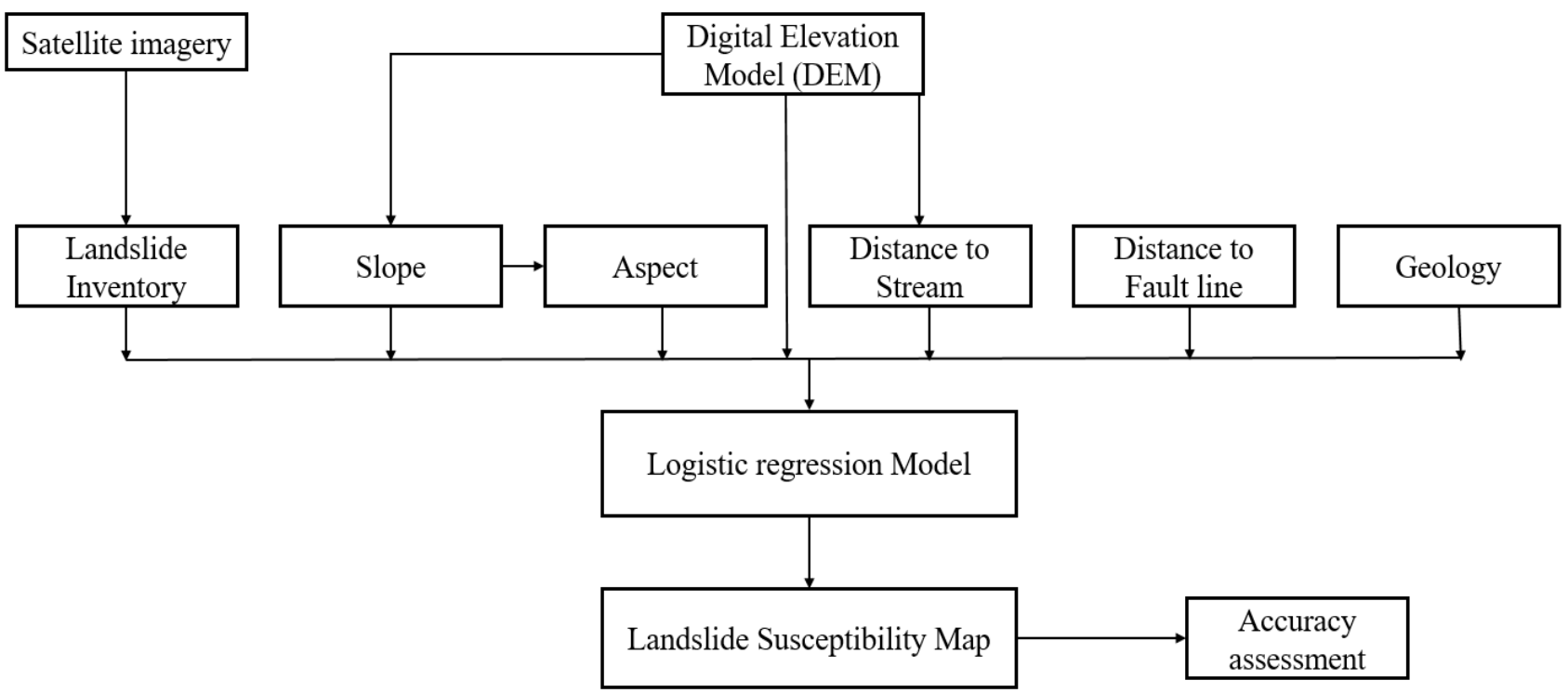

Figure 2: Methodology Flowchart of research

This model gives us coefficient from every independent factor and that factor shows us the importance of the individual factor, the positive value of coefficient shows that the factor has higher importance in the occurrence of landside. In contrast the negative value of coefficient means that factor decrease the probability of landslide in the area. For this study we have taken $70 \%$ of the data for training for the model and $30 \%$ for the validation of the model performance. The factors which significance is lower than 0.05 were used in the model to develop landslide susceptibility map.

After the output from the logistic model the validation data was used using receiver operation characteristics (ROC) curve to see the accuracy of the model performance.

\section{Results and Discussions}

\section{Landslide Mapping}

Landslide inventory is considered as the base for the further analysis about the landslide like landside susceptibility mapping or landside hazard assessment for future disaster. In this study we have support vector machine (SVM) classifier for the landslide mapping which can helped us to detect landslide area in the mountainous area on the basis of spectral reflectance of the area. We have used landslide class as 1 of the lands cover class and later on we have convert it to vector data for further analysis. In this study as the spatial resolution of the data is very high so we were able to mapped small landslides also which couldn't be mapped by other free source dataset like (ASTER and Landsat series). The total number of 51460 small and large landslides are mapped using this technique which are shown in figure 1 .

\section{Logistic regression Model}

Logistic regression model is mostly used model to develop landside susceptibly map worldwide. According to this model we have the presence and absence of the landside so for that model we need 0 and 1 data. In this case the 1 shows the presence of the landside and 0 shows the absence of landslide in the area and that data is furtherly used with the predictors variable to develop coefficients to develop landslide susceptibility map. Below is the table which shows the coefficient of every Influential factor with degree of freedom and significance of individual factor.

\begin{tabular}{|l|r|r|r|r|}
\hline $\begin{array}{l}\text { Influential } \\
\text { Factors }\end{array}$ & $\begin{array}{l}\text { Estimated } \\
\text { Coefficients }\end{array}$ & S.E & $\begin{array}{l}\text { Degree } \\
\text { of } \\
\text { freedom }\end{array}$ & Significance \\
\hline Elevation & 0.12 & .000 & 1 & .000 \\
\hline Slope & 0.074 & .001 & 1 & .000 \\
\hline Aspect & 0.001 & .000 & 1 & .000 \\
\hline Geology & 0.97 & .002 & 1 & .000 \\
\hline $\begin{array}{l}\text { Distance to } \\
\text { Stream }\end{array}$ & .153 & .015 & 1 & .000 \\
\hline $\begin{array}{l}\text { Distance to } \\
\text { Fault line }\end{array}$ & 0.950 & .019 & 1 & .000 \\
\hline Constant & 2.92 & .087 & 1 & .000 \\
\hline
\end{tabular}

Table 1: Estimated Coefficients from the logistic regression model.

From this table we can analyse that the higher coefficient is carried by geology which is " 0.97 " which shows that geology is the most important and increasing the occurrence of landslide in 
the area. The least influential factor from those all factors is Aspect with the estimated coefficient of " 0.001 ".

\section{Landslide Susceptibility Mapping}

As in the landslide susceptibility map the area is divided into different zones which define the probability of the landside in the area. So according to the probability of the landslide we are having the pixel value for whole area from 0 to 1 , so the pixel value near 1 means that $(0.8$ or 0.9$)$ then the area will be more prone to the landslide. But if the pixel value is near to 0 so the area will be less susceptible to landslide.

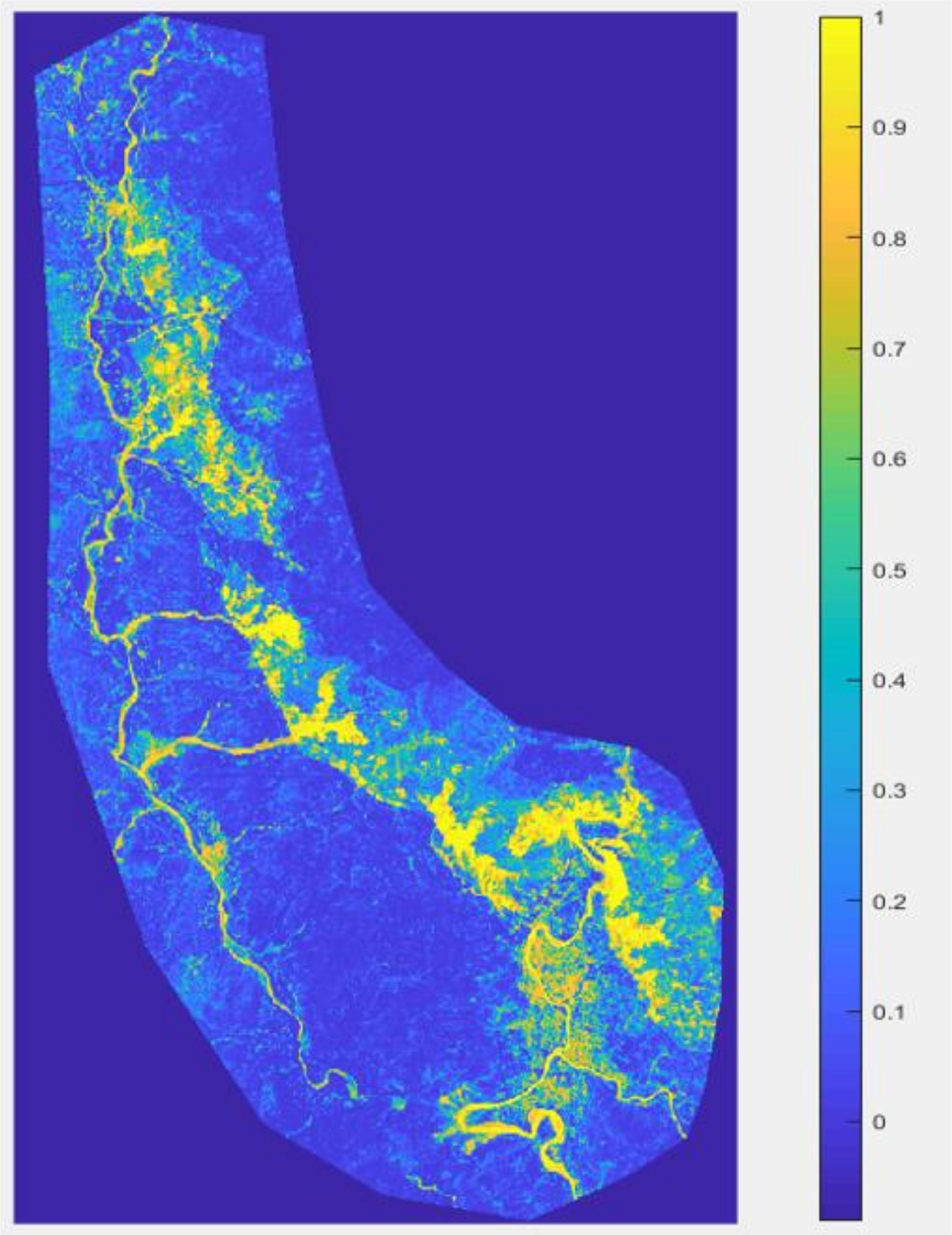

Figure 3: Landslide Susceptibility map derived from logistic regression model

Here in figure 3 we can see that the near to the Muzaffarabad fault line is more prone to landslide in the future. The area along the Muzaffarabad fault line is continuously effected by rainfall triggered landslide. The geology of the area contain different geological formations by the most affected area geological formations are Murree and Muzaffarabad formations which are more soft in nature. Kamp et al. (2008) has used the multi criteria evaluation (MCE) technique for landslide susceptibility mapping and they concluded that the most influential factor causing the landslide is geology of the area which is in agreement with this study. Basharat et al. (2014) findings shows that by increasing the distance, the effect of landslide effected area is decreasing but this also depend on the geographical composition of the area. As in the table 1 shown that fault line got the $2^{\text {nd }}$ highest coefficient, Gorum et al. (2011) has done the study on Wenchuan earthquake and find that there is strong correlation in the spatial pattern of landslide and distance to fault line.

As we already discussed in methodology section that we have used $30 \%$ for validation of the model output, so after getting the landslide susceptibly map from logistic regression model we have validated our results and got the accuracy of $92 \%$. 
Considering the high performance of the model the study shows that model has highlighted the most prone areas in the high susceptible zone. Raja et al. (2017) has done the study on Sera River basin to develop landsdlie suseptablity map using logistic regreesion model and got the accuracy of $83 \%$. The ROC curve figure is shown in figure 4 .

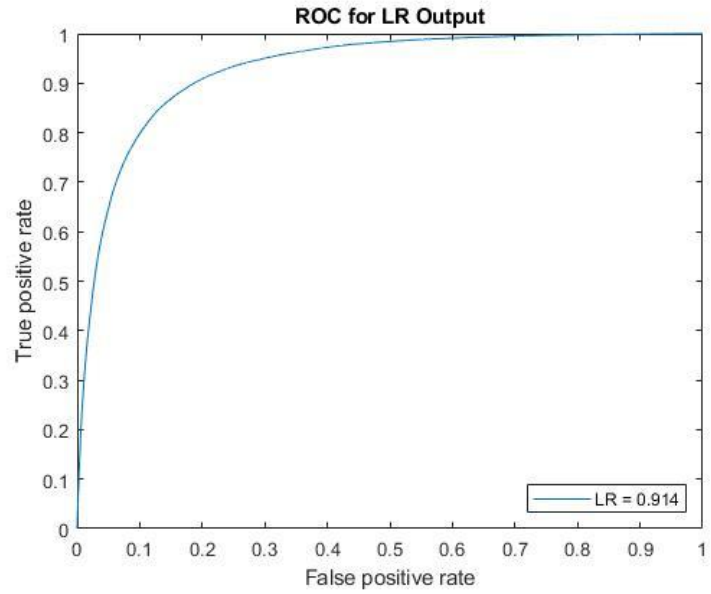

Figure 4: ROC accuracy curve of landslide susceptibility map

\section{Conclusion}

The study presented landslide inventory and susceptibility map for the area of Muzaffarabad and Balakot using high resolution image. The high resolution imagery for landslide inventory leads to more accurate landslide inventory and also mapped small landside. The smaller landslide mapped in this study is $2.01 \mathrm{~m}^{2}$. In this study we find that geology is the important influential factor and the $2^{\text {nd }}$ important factor is distance to the fault line and the most affected area from landslide is along the Muzaffarabad fault line. The developed landside susceptibility map was validated using the $30 \%$ of the landslide data and got the accuracy of $92 \%$. The developed landslide susceptibility map can be further used for planning and infrastructure in the area.

\section{References}

Ali, M. Z., et al. (2017). "Impact assessment of spatial resolution on landslide inventories: A case study of Muzaffarabad city." 50(2): 114-124.

Basharat, M., et al. (2014). "Spatial distribution analysis of mass movements triggered by the $2005 \mathrm{Kashmir}$ earthquake in the Northeast Himalayas of Pakistan." Geomorphology 206: 203214.

Basharat, M., et al. (2016). "Landslide susceptibility mapping using GIS and weighted overlay method: a case study from NW Himalayas, Pakistan." 9(4): 292.

Bui, D. T., et al. (2015). "A novel hybrid evidential belief function-based fuzzy logic model in spatial prediction of rainfallinduced shallow landslides in the Lang Son city area (Vietnam)." Geomatics, Natural Hazards and Risk 6(3): 243-271.

Chigira, M., et al. (2010). "Landslides induced by the 2008 Wenchuan earthquake, Sichuan, China." Geomorphology 118(3): 225-238.

Devkota, K. C., et al. (2013). "Landslide susceptibility mapping using certainty factor, index of entropy and logistic regression models in GIS and their comparison at Mugling-Narayanghat road section in Nepal Himalaya." Natural hazards 65(1): 135165 .

Dragićević, S., et al. (2015). "GIS-based multicriteria evaluation with multiscale analysis to characterize urban landslide susceptibility in data-scarce environments." Habitat International 45: 114-125.

Gorum, T., et al. (2011). "Distribution pattern of earthquakeinduced landslides triggered by the 12 May 2008 Wenchuan earthquake." Geomorphology 133(3): 152-167.

Kamp, U., et al. (2008). "GIS-based landslide susceptibility mapping for the 2005 Kashmir earthquake region." Geomorphology 101(4): 631-642.

Kavzoglu, T., et al. (2014). "Landslide susceptibility mapping using GIS-based multi-criteria decision analysis, support vector machines, and logistic regression." Landslides 11(3): 425-439.

Kavzoglu, T., et al. (2015). "Selecting optimal conditioning factors in shallow translational landslide susceptibility mapping using genetic algorithm." Engineering Geology 192: 101-112.

Lodhi, M. A. (2011). "Earthquake-induced landslide mapping in the western Himalayas using medium resolution ASTER imagery." International Journal of Remote Sensing 32(19): 53315346.

Martha, T. R., et al. (2010). "Characterising spectral, spatial and morphometric properties of landslides for semi-automatic detection using object-oriented methods." 116(1-2): 24-36.

Mohammady, M., et al. (2012). "Landslide susceptibility mapping at Golestan Province, Iran: a comparison between frequency ratio, Dempster-Shafer, and weights-of-evidence models." Journal of Asian Earth Sciences 61: 221-236.

Owen, L. A., et al. (2008). "Landslides triggered by the 8 October 2005 Kashmir earthquake." Geomorphology 94(1): 1-9.

Pourghasemi, H., et al. (2013). "Landslide susceptibility mapping by binary logistic regression, analytical hierarchy process, and statistical index models and assessment of their performances." Natural hazards 69(1): 749-779.

Pourghasemi, H. R., et al. (2012). "Application of fuzzy logic and analytical hierarchy process (AHP) to landslide susceptibility mapping at Haraz watershed, Iran." Natural hazards 63(2): 965996.

Raja, N. B., et al. (2017). "Landslide susceptibility mapping of the Sera River Basin using logistic regression model." Natural hazards 85(3): 1323-1346.

Shafique, M., et al. (2016). "A review of the 2005 Kashmir earthquake-induced landslides; from a remote sensing prospective." Journal of Asian Earth Sciences 118: 68-80.

Soofastaei, A., et al. (2016). "Development of a multi-layer perceptron artificial neural network model to determine haul trucks energy consumption." International Journal of Mining Science and Technology 26(2): 285-293. 
Stumpf, A. and N. Kerle (2011). "Object-oriented mapping of landslides using Random Forests." Remote Sensing of Environment 115(10): 2564-2577.

Wei, L.-W., et al. (2018). "Adopting the I 3-R 24 rainfall index and landslide susceptibility for the establishment of an early warning model for rainfall-induced shallow landslides." Natural Hazards \& Earth System Sciences 18(6).

Weissel, J. K. and C. P. Stark (2001). Landslides triggered by the 1999 Mw7. 6 Chi Chi earthquake in Taiwan and their relationship to topography. Geoscience and Remote Sensing Symposium, 2001. IGARSS'01. IEEE 2001 International, IEEE.

$\mathrm{Xu}, \mathrm{C}$., et al. (2018). "Landslides triggered by the $2016 \mathrm{Mj} 7.3$ Kumamoto, Japan, earthquake." Landslides 15(3): 551-564.

Yalcin, A., et al. (2011). "A GIS-based comparative study of frequency ratio, analytical hierarchy process, bivariate statistics and logistics regression methods for landslide susceptibility mapping in Trabzon, NE Turkey." Catena 85(3): 274-287.

Yilmaz, I. (2009). "A case study from Koyulhisar (Sivas-Turkey) for landslide susceptibility mapping by artificial neural networks." Bulletin of Engineering Geology and the Environment 68(3): 297-306

Yilmaz, I. (2010). "Comparison of landslide susceptibility mapping methodologies for Koyulhisar, Turkey: conditional probability, logistic regression, artificial neural networks, and support vector machine." Environmental Earth Sciences 61(4): 821-836. 